\title{
Multi-Region Combined Heat and Power Economic Emission Dispatch
}

\author{
Suman Kumar Dey, Deba Prasad Dash, Mousumi Basu
}

\begin{abstract}
Multi-Region Combined Heat and Power Economic Emission Dispatch (MRCHPEED) is an important chore in operational and planning problem. The valve point impact and restricted useful zone of regular thermal generators have been contemplated. In this work, Nondominated Sorting Genetic Algorithm-II (NSGA-II) is proposed for illuminating confounded MRCHPEED problem where power and heat generations have been distributed amongst the all committed units so that fuel cost and outflow echelon have been streamlined in chorus though gratifying every single operational requirement. The research consequence of a two-region investigation framework achieved from the prescribed technique are coordinated up to those acquired from Strength Pareto Evolutionary Algorithm 2 (SPEA 2).
\end{abstract}

Index Terms- banished useful region; co-generation units; Multi-region; tie line imperatives; valve point effect.

\section{INTRODUCTION}

Economic dispatch (ED) allocates the generation level of all devoted turbines in a most price- effective way whilst gratifying numerous constraints in a solo structure.

In preferred, generating units are separated among several power production areas connected by using interconnections. Multi-Region Economic Dispatch (MRED) is a growth of lone place economic dispatch. MRED reveals the electricity creation stage along with communication of energy among areas for reducing cost of all sections while satisfying miscellaneous constraint. Different strategies [1]-[8] are converse to explain MRED issue.

Vestige fuel is transformed into electricity in unproductive style. The best part of electricity production desecrated during the technique of change is high temperature. Creating power from a particular fuel source, for example, flammable gas, biomass, coal progress the use of flow due to the difference in temperature along with usefulness of the renovation method is accelerated. In contrast with different variety of energy transmitter, the usefulness of energy of cogeneration is extra which creates less significant pollution. The Combined Heat and Power Economic Dispatch (CHPED) method implies power and heat creation accordingly that production billing is minimized along with satisfying miscellaneous constraint. Different proposal have already been proposed to solve CHPED issues and those are mentioned in reference section.

Revised Manuscript Received on February 05, 2020.

* Correspondence Author

Suman Kumar Dey, pursuing his Ph.D. in Electrical Engineering Department of Power Engineering, Jadavpur University, Kolkata.

Deba Prasad Dash, working as Associate Professor, Department of Electrical Engineering, Government College of Engineering, Kalahandi.

Mousumi Basu, professor Department of Power Engineering Jadavpur Universty. Kolkata

(C) The Authors. Published by Blue Eyes Intelligence Engineering and Sciences Publication (BEIESP). This is an open access article under the CC BY-NC-ND license (http://creativecommons.org/licenses/by-nc-nd/4.0/)
Huge incorporated power system is generally comprised of divergent locales dependent on an assortment of model for instance topographical, functional, forecast and administration.

Every one of these areas has been correlated to its connecting section along with interconnections. Each locale has its capacity and heat creation and energy and heat requirement.

Limiting the complete cost for every spot through stacking of every dedicated generating units along with cogeneration and heat-only units in this way that true power equilibrium limit, heat stability imperatives, production boundary requirements, heat production limit requirements with interconnection limit requirements have been fulfilled while from a particular fuel source, for example, flammable gas, biomass, coal are going in the course of limited heat vs. true power plane is the main point of Multi-Region Combined Heat and Power Economic Dispatch (MRCHPED) .

Electric power plants based on fossil-fuel release a variety of pollutants which creates air pollution in the ambiance. Declining ambiance greenhouse gasses is another challenge for different power producers. The 1990 Clean Air Act is proposed for reducing atmospheric pollution. So today's civilization wants adequate and safe electricity at the costeffective as well as minimum echelon of greenhouse gasses.

Various methods are proposed to decrease ambience greenhouse gasses [9]-[15]. Among these tactics, dispatching taking into emission consideration is preferable.

The proposed approach is an expansion of Multi-Region Combined Heat and Power Economic Dispatch (MRCHPED) trouble. It plans a wide range of committed coal-fired generating units outputs, co-generation unit outputs, heat-only unit outputs and interchange power amongst regions with forecasted active power demand and heat request with the end goal that all out cost and outflow echelon in all sections are streamlined simultaneously satisfying an assortment of requirements.

This paper suggests NSGA-II to solve complicated multiregion combined heat and power economic emission dispatch (MRCHPEED) issues. For the given system, each region comprises coal-fired generating parts, co-generation parts and heat only parts. Every locale of the framework includes generation entity, co-generation entity and heat only entity.

To triumph over intricacy of binary version for trading with unremitting explore break with big proportions, Real-Coded Genetic Algorithm (RCGA) [16] is exploited. The Simulated Binary Crossover (SBX) and polynomial mutation are used here. 
The recommended method is confirmed by relating it with two-region analysis scheme. Analysis outcome attained in the course of NSGA-II procedure are matched up through the result which are attained from Strength Pareto Evolutionary Algorithm 2 (SPEA2).

\section{PROBLEM FORMULATION}

Here framework consisting of generation segment, segment related to power from a particular fuel source, for example, flammable gas, biomass, coal and heat-only segment has been taken into consideration. Figure 1 uncovers heat-power reasonable serviceable zone of a joined cycle co-age unit. The warmth and force preparations are inseparable. The heat-power practical functional zone has been encompassed by the wilderness curve ABCDEF.

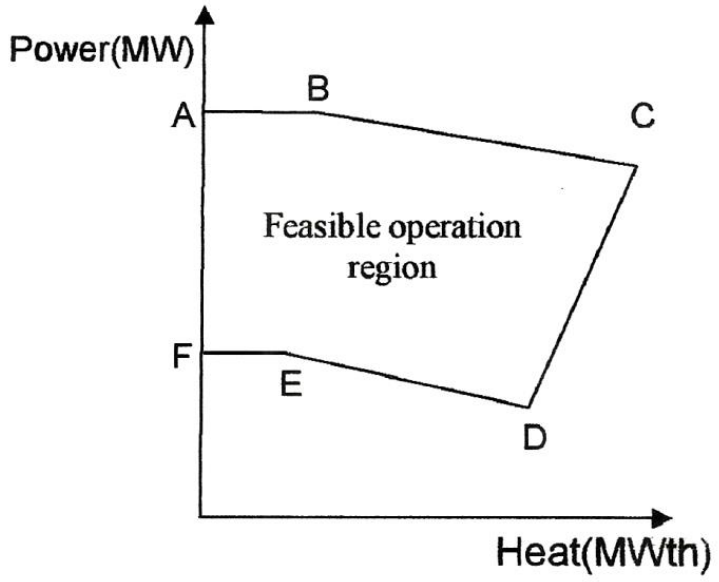

Fig.1. Heat-Active power viable workable area for a cogeneration

The power output of the thermal generators and the heat output of heat-only units are bounded by their individual maximum and minimum frontiers. The power is produced by thermal generators and co-generation units and the heat is produced by co-generation units and heat-only units.

The MRCHPEED issue chooses the active power and heat creation with the goal that the complete cost and outflow of all locales is upgraded through running every dedicated generating units, units produced power from a particular fuel source, for example, flammable gas, biomass, coal and heat only units in this way where different limitation are fulfilled but units produced power from a particular fuel source, for example, flammable gas, biomass, coal are attempted in an encompassed heat in opposition to power plane. Here MRCHPEED issue is communicated as:

\section{Objectives}

\section{A. Cost}

The total price is stated as

$$
\begin{aligned}
& C_{\mathrm{T}}=\sum_{i=1}^{\mathrm{N}_{\mathrm{A}}} \sum_{j=1}^{\mathrm{N}_{t i}}\left[a_{i j}+b_{i j} \mathrm{P}_{t i j}+c_{i j} \mathrm{P}_{t i j}^{2}+\left|d_{i j} \times \sin \left\{e_{i j} \times\left(\mathrm{P}_{t i j}^{\min }-\mathrm{P}_{t i j}\right)\right\}\right|\right. \\
& +\sum_{i=1}^{\mathrm{N}_{\mathrm{A}}} \sum_{j=1}^{\mathrm{N}_{c i}}\left[\alpha_{i j}+\beta_{i j} \mathrm{P}_{c i j}+\gamma_{i j} \mathrm{P}_{c i j}^{2}+\right.
\end{aligned}
$$

$$
\begin{aligned}
& \left.\delta_{i j} \mathrm{H}_{c i j}+\varepsilon_{i j} \mathrm{H}_{c i j}^{2}+\xi_{i j} \mathrm{P}_{c i j} \mathrm{H}_{c i j}\right]+ \\
& \sum_{i=1}^{\mathrm{N}_{\mathrm{A}}} \sum_{j=1}^{\mathrm{N}_{h i}}\left[\phi_{i j}+\eta_{i j} \mathrm{H}_{h i j}+\lambda_{i j} \mathrm{H}_{h i j}^{2}\right]
\end{aligned}
$$

\section{B. Emission}

The ambience green house gases consisting of different air pollutants produced as a result of coalfired generating unit is represented one by one. On the other hand, for assessment cause, the whole secretion of these green house gases is affirmed as the summation of a quadratic and an exponential characteristic. The general discharge from thermal segments, cogeneration segments and heat-only segments in the system may be stated as

$$
\begin{aligned}
& E_{\mathrm{T}}=\sum_{i=1}^{\mathrm{N}_{\mathrm{A}}} \sum_{j=1}^{\mathrm{N}_{t i}}\left[\mu_{i j}+\kappa_{i j} \mathrm{P}_{t i j}+\pi_{i j} \mathrm{P}_{t i j}^{2}+\sigma_{i j} e^{\left(\theta_{i j} \mathrm{P}_{t i j}\right)}\right]+ \\
& \sum_{i=1}^{\mathrm{N}_{\mathrm{A}}} \sum_{j=1}^{\mathrm{N}_{c i}}\left[\tau_{i j} \mathrm{P}_{c i j}\right]+\sum_{i=1}^{\mathrm{N}_{\mathrm{A}}} \sum_{j=1}^{\mathrm{N}_{h i}}\left[\rho_{i j} \mathrm{H}_{h i j}\right]
\end{aligned}
$$

\section{Constraints \\ C. Power equilibrium constraints}

The general real power production for every generating section and co-generation section need to be same to the region where real power utility in the company of the reflection of incoming and outgoing real power and is acknowledged in the following way:

$$
\sum_{j=1}^{\mathrm{N}_{t i i}} \mathrm{P}_{t i j}+\sum_{j=1}^{\mathrm{N}_{c i}} \mathrm{P}_{c i j}=\mathrm{P}_{D i}+\sum_{k, k \neq i} \mathrm{~T}_{i k} \quad i \in \mathrm{N}_{\mathrm{A}}
$$

Where $\mathrm{T}_{i k}$ is the interconnection real power transmission in between section $i$ to section $k . \mathrm{T}_{i k}$ is positive at the same time as energy transfer from section $i$ to section $k$ and $\mathrm{T}_{i k}$ is negative while energy transfer from section $k$ to section $i$.

\section{Interconnection power capacity constraints}

Power transmission through interconnection $\mathrm{T}_{x y}$ from section $x$ to section $y$ should lie within the interconnection real power transfer capacity boundary.

$$
-\mathrm{T}_{x y}^{\max } \leq \mathrm{T}_{x y} \leq \mathrm{T}_{x y}^{\max }
$$

Where $\mathrm{T}_{i k}^{\mathrm{max}}$ the active power flow is limit from region $i$ to region $k$ and $-\mathrm{T}_{i k}^{\max }$ is the active power flow limit from region $k$ to region $i$.

\section{E. Capability frontiers of thermal generators}

$$
\mathrm{P}_{t i j}^{\min } \leq \mathrm{P}_{t i j} \leq \mathrm{P}_{t i j}^{\max }, i \in \mathrm{N}_{\mathrm{A}} \text { and } j \in \mathrm{N}_{t i}
$$




\section{F. Restricted effective region of coal-fired generating units}

The physically possible functional section of the $j$ th generation unit in the section $i$ with restricted achievable vicinity is affirmed as:

$$
\begin{aligned}
& \mathrm{P}_{t i j}^{\min } \leq \mathrm{P}_{t i j} \leq \mathrm{P}_{t i j, 1}^{l} \\
& \mathrm{P}_{t i j, m-1}^{u} \leq \mathrm{P}_{t i j} \leq \mathrm{P}_{t i j, m}^{l} ; m=2,3, \ldots, n_{i j} \\
& \mathrm{P}_{t i j, n_{i j}}^{u} \leq \mathrm{P}_{t i j} \leq \mathrm{P}_{t i j}^{\max }
\end{aligned}
$$

Where $m$ signifies the quantity of restricted achievable vicinity. $\mathrm{P}_{t i j, m-1}^{u}$ is the maximum limit of $(m-1)$ th proscribed workable area of $j$ th thermal generator in region i . $\mathrm{P}_{t i j, m}^{l}$ is the minimum limit of $m$ th proscribed workable area of $j$ th thermal generator in region $i$. Total number of proscribed workable areas of $j$ th thermal generator in region $i$ is $n_{i j}$.

\section{G. Heat equilibrium constraints}

$$
\sum_{j=1}^{\mathrm{N}_{c i}} \mathrm{H}_{c i j}+\sum_{j=1}^{\mathrm{N}_{h i}} \mathrm{H}_{h i j}=\mathrm{H}_{D i}+\sum_{k, k \neq i} \mathrm{H}_{i k} \quad i \in \mathrm{N}_{\mathrm{A}}
$$

(7)

Where $\mathrm{H}_{i k}$ is the temperature transfer through interconnection from section $i$ to section $k . \mathrm{H}_{i k}$ is positive when temperature depart from section $i$ to section $k$ and $\mathrm{H}_{i k}$ is negative while temperature depart from section $k$ to section $i$.

\section{H. Tie line heat capacity constraints}

Temperature transfer through interconnection $\mathrm{H}_{i k}$ from region $i$ to region $k$ should be within the tie line heat transfer capacity limits.

$$
-\mathrm{H}_{i k}^{\max } \leq \mathrm{H}_{i k} \leq \mathrm{H}_{i k}^{\max }
$$

Where $\mathrm{H}_{i k}^{\max }$ is the heat transfer capability in between section $i$ to section $k$ and $-\mathrm{H}_{i k}^{\max }$ is the heat transfer capability in between section $k$ to region $i$.

\section{Capability frontiers of cogeneration units}

Heat and power outputs of the units produced power from a particular fuel source, for example, flammable gas, biomass and coal are undividable and one output interrupt with other $\mathrm{P}_{c}^{\min }\left(\mathrm{H}_{c}\right) \mathrm{P}_{c}^{\max }\left(\mathrm{H}_{c}\right) \mathrm{H}_{c}^{\min }\left(\mathrm{P}_{c}\right)$ and $\mathrm{H}_{c}^{\max }\left(\mathrm{P}_{c}\right)$ are the linear primary constraints which render the possible effective part of the cogeneration segments.

$$
\mathrm{P}_{c i j}^{\min }\left(\mathrm{H}_{c i j}\right) \leq \mathrm{P}_{c i j} \leq \mathrm{P}_{c i j}^{\max }\left(\mathrm{H}_{c i j}\right), i \in \mathrm{N}_{\mathrm{A}} \text { and } j \in \mathrm{N}_{c i}
$$

$$
\mathrm{H}_{c i j}^{\min }\left(\mathrm{P}_{c i j}\right) \leq \mathrm{H}_{c i j} \leq \mathrm{H}_{c i j}^{\max }\left(\mathrm{P}_{c i j}\right), i \in \mathrm{N}_{\mathrm{A}} \text { and } j \in \mathrm{N}_{c i}
$$

\section{J. Fabrication frontiers of heat-only units}

$$
\mathrm{H}_{h i j}^{\min } \leq \mathrm{H}_{h i j} \leq \mathrm{H}_{h i j}^{\max }, i \in \mathrm{N}_{\mathrm{A}} \text { and } j \in \mathrm{N}_{h i}
$$

\section{NONDOMINATED SORTING GENETIC ALGORITHM-II}

N. Srinivas and K. Deb [7] recognized an algorithm based on genetic technique abbreviated as "NSGA" to compete with multifaceted optimization issues. Nondomination is used as grading criteria of result, and fitness distribution is used for diversification control in the investigated section. Like NSGA is incredibly responsive to fitness distribution factors, Deb et al. [8] established nondomoinated sorting genetic algorithm-II (NSGA-II), which produces advance consistent way out quickly than its ancestor. Owing to inadequacy of space details of NSGA-II cannot be provided in this paper.

\section{SIMULATION RESULTS}

The recommended NSGA-II is used to solve a complicated MRCHPEED problem. Here a system has been considered having two separate frameworks. Simulation results have been utilized to coordinate the viability of the suggested NSGA-II along with strength pareto evolutionary algorithm 2 (SPEA 2).Fuel charge and discharge are major conflicting issues. To illuminate opposing connections among the goal capacities, every one for example fuel cost and discharge is limited independently by utilizing genuine coded hereditary calculation (RCGA). The populace size, most extreme number of cycles, hybrid and transformation probabilities are preferred like 100, 300, 0.9 and 0.2 separately. NSGA-II is confirmed to improve different goals for example fuel cost and discharge at the same time. To analyze the outcomes, SPEA 2 is utilized to take care of this issue. The population size, upper limit of iterations, crossover and mutation probabilities are preferred 20, 30, 0.9 and 0.2 respectively in NSGA-II and SPEA 2.The NSGA-II, SPEA 2 and RCGA are abused by using MATLAB 7.5 on a PC (Dual core, 1TB, 3.3 GHz).

Section 1 consist of of 13 Nos of generation units with restricted effective area and valve point effect, 6 Nos of cogeneration units and 5 Nos of heat-only units. Detailed data is summarized in Table A.1 and Table A.2 in the appendix. The other data of co-generation units is taken from [4].

Section 2 comprises 26 Nos of conventional generation unit restricted effective area and valve point effect, 12 Nos of units which produced power from a particular fuel source, for example, flammable gas, biomass, coal and 10 heat-only units. Records of section 2 are managed by replicating records of section 1 . The active power stream border commencing section 1 to section 2 or commencing section 2 to section 1 is $300 \mathrm{MW}$. The heat stream border commencing section 1 to section 2 or commencing section 2 to section 1 is $300 \mathrm{MWth}$. 
Whole active power and heat requirement separated between section 1 and section 2 are $30 \%$ and $70 \%$ respectively. Total active power requirement is $7500 \mathrm{MW}$ and entire heat requirement is 5000 MWth.

Multi-region combined heat power economic dispatch problem and multi-region combined heat and power emission dispatch problem are solved by using RCGA. It is examined that under multi-region combined heat and power economic dispatch, total cost is 207472 \$/hr and emission is $287.1266 \mathrm{Kg} / \mathrm{hr}$. But price boosts to $521942 \mathrm{\$} / \mathrm{hr}$ and emission reduces to $183.8696 \mathrm{Kg} / \mathrm{hr}$ in case of multi-region combined heat and power emission dispatch.

Multi-region combined heat power economic emission dispatch (MRCHPEED) issue is fathomed via using recommended NSGA-II and SPEA 2. Contingent upon MRCHPEED using NSGA-II, fuel cost is 305630 \$/hr and emission is $241.4702 \mathrm{Kg} / \mathrm{hr}$. MRCHPEED using SPEA 2, fuel charge is $317390 \$ / \mathrm{hr}$ and discharge is $241.9414 \mathrm{Kg} / \mathrm{hr}$.

The active power and heat production of section 1 and section 2 accomplished from the multi-region combined heat and power economic dispatch along with others by utilizing NSGA-II and SPEA 2 have been pointed out in Table I and Table II correspondingly.

Fuel cost, emission, interconnection active power transmission and interconnection heat transmission acquired commencing multi-region combined heat and power economic dispatch problem along with others are accumulated inside chart 3 as given. The cost convergence and emission convergence characteristics acquired by utilizing RCGA has been revealed in Fig. 2 and Fig. 3 respectively. Figure 4 reveals the distribution of 20 nondominated solutions attained in the final iteration of recommended NSGA-II and SPEA2 attained from MRCHPEED.

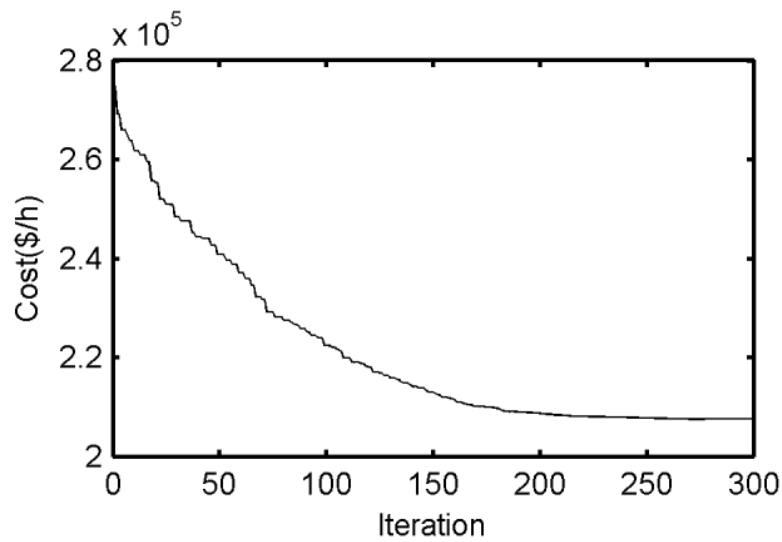

Fig. 2. Cost convergence characteristic

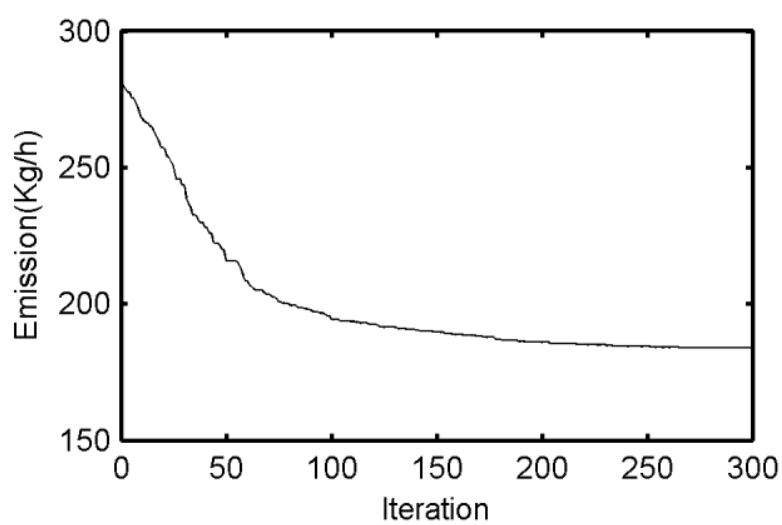

Fig. 3. Emission convergence characteristic

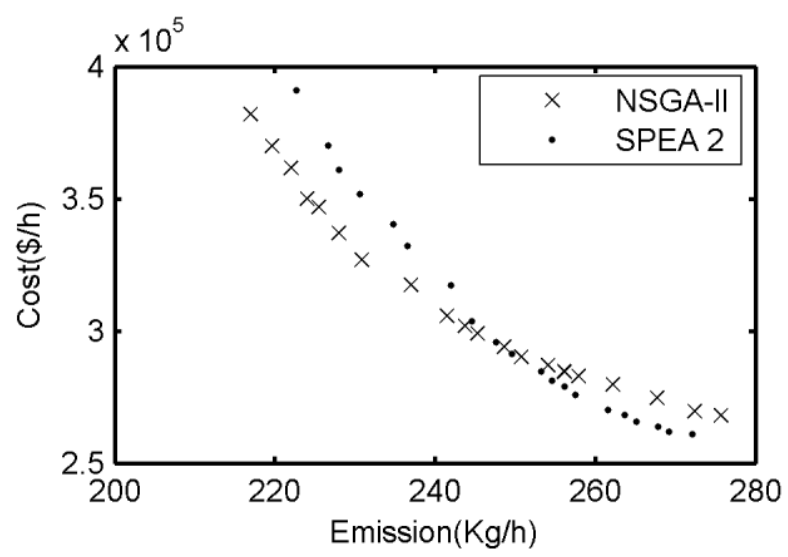

Fig. 4. Pareto-optimal front of the final iteration

Table III: Assessments of concert

\begin{tabular}{|c|c|c|c|c|}
\hline \multirow[t]{2}{*}{ Parameter } & \multirow{2}{*}{$\begin{array}{c}\text { Multi- } \\
\text { region } \\
\text { combined } \\
\text { heat and } \\
\text { power } \\
\text { economic } \\
\text { dispatch }\end{array}$} & \multirow{2}{*}{$\begin{array}{l}\text { Multi- } \\
\text { region } \\
\text { combined } \\
\text { heat and } \\
\text { power } \\
\text { emission } \\
\text { dispatch }\end{array}$} & \multicolumn{2}{|c|}{$\begin{array}{l}\text { Multi-region } \\
\text { combined heat and } \\
\text { power economic } \\
\text { emission dispatch }\end{array}$} \\
\hline & & & $\begin{array}{c}\text { NSGA- } \\
\text { II }\end{array}$ & SPEA 2 \\
\hline Cost $(\$ / h)$ & 207472 & 521942 & 305630 & 317390 \\
\hline $\begin{array}{c}\text { Emission } \\
(\mathrm{Kg} / \mathrm{h})\end{array}$ & 287.1266 & 183.8696 & 241.4702 & 241.9414 \\
\hline $\begin{array}{c}\mathrm{T}_{12} \\
(\mathrm{MW})\end{array}$ & 42.1859 & 246.8647 & 200.0926 & 100.9626 \\
\hline $\begin{array}{c}\mathrm{H}_{12} \\
\text { (MWth) }\end{array}$ & 173.3398 & 116.7972 & $\begin{array}{c}- \\
271.5332\end{array}$ & 149.8350 \\
\hline
\end{tabular}


Table I: Active power production (MW) and Heatproduction (MWth) of section 1 acquired from multi-region combined heat and power dispatch

\begin{tabular}{|c|c|c|c|}
\hline \multirow[t]{2}{*}{$\begin{array}{l}\text { Economic } \\
\text { Dispatch }\end{array}$} & \multirow[t]{2}{*}{$\begin{array}{l}\text { Emission } \\
\text { Dispatch }\end{array}$} & \multicolumn{2}{|c|}{$\begin{array}{c}\text { Economic Emission } \\
\text { Dispatch }\end{array}$} \\
\hline & & NSGA II & SPEA 2 \\
\hline$P_{t 1} 175.3269$ & 131.3751 & 238.6961 & 121.4263 \\
\hline$P_{t 2} 240.2568$ & 220.0097 & 169.3303 & 269.6463 \\
\hline$P_{t 3} 262.1979$ & 225.0039 & 252.0785 & 259.3150 \\
\hline$P_{t 4} 122.4446$ & 148.1775 & 137.6074 & 165.9348 \\
\hline$P_{t 5} 171.2847$ & 149.4530 & 180.0000 & 100.9899 \\
\hline $\mathrm{P}_{t 6} 106.1885$ & 151.0677 & 107.4919 & 139.3710 \\
\hline$P_{t 7} 137.3948$ & 76.0717 & 86.5014 & 60.0000 \\
\hline $\mathrm{P}_{t 8} 143.3005$ & 76.1873 & 136.9679 & 60.0000 \\
\hline $\mathrm{P}_{t 9} 131.5079$ & 75.4632 & 120.3673 & 71.5266 \\
\hline$P_{t 10} 77.5608$ & 96.4404 & 101.4402 & 106.8052 \\
\hline$P_{t 11} 75.2351$ & 97.5335 & 119.5742 & 120.0000 \\
\hline$P_{t 12} 55.0000$ & 77.5996 & 57.8323 & 94.8652 \\
\hline$P_{t 13} 55.9525$ & 77.0394 & 57.3955 & 81.6566 \\
\hline $\mathrm{P}_{c 1} 147.0936$ & 246.9580 & 177.5651 & 185.7836 \\
\hline $\mathrm{P}_{c 2} \quad 87.0206$ & 125.7733 & 93.0103 & 82.0021 \\
\hline $\begin{array}{ll}P_{c 3} & 170.5433\end{array}$ & 247.0000 & 225.3918 & 239.8347 \\
\hline $\mathrm{P}_{c 4} \quad 83.6526$ & 125.7509 & 119.4748 & 72.5157 \\
\hline $\mathrm{P}_{c 5} \quad 10.7658$ & 60.0000 & 33.4432 & 39.6768 \\
\hline $\mathrm{P}_{c 6} \quad 39.4589$ & 89.9604 & 35.9243 & 79.6128 \\
\hline $\mathrm{H}_{c 1} 141.7551$ & 0 & 65.3837 & 53.9485 \\
\hline $\mathrm{H}_{c 2} 115.5269$ & 32.3889 & 48.3176 & 80.0202 \\
\hline $\mathrm{H}_{c 3} 154.8795$ & 0 & 0 & 0 \\
\hline $\mathrm{H}_{c 4} 112.6807$ & 32.1705 & 13.4316 & 50.2808 \\
\hline $\mathrm{H}_{c 5} 40.3284$ & 0 & 0.0941 & 28.3155 \\
\hline $\mathrm{H}_{c 6} 21.9781$ & 24.1873 & 5.1975 & 0.0005 \\
\hline $\mathrm{H}_{h 1} \quad 60.0000$ & 1.4000 & 36.7000 & 56.7000 \\
\hline $\mathrm{H}_{h 2} 59.9822$ & 0 & 60.0000 & 44.7000 \\
\hline $\mathrm{H}_{h 3} 119.9857$ & 0 & 105.1000 & 87.2000 \\
\hline $\mathrm{H}_{h 4} 119.9984$ & 1.0000 & 120.0000 & 112.2000 \\
\hline $\mathrm{H}_{h 5} 726.2247$ & 1525.60 & 774.3 & 1136.4 \\
\hline
\end{tabular}

Table II: Power production (MW) and heat production (MWth) of section 2 acquired from multi-region combined heat and power dispatch.

\begin{tabular}{|c|c|c|c|}
\hline \multirow[t]{2}{*}{$\begin{array}{l}\text { Economic } \\
\text { Dispatch }\end{array}$} & \multirow[t]{2}{*}{$\begin{array}{l}\text { Emission } \\
\text { Dispatch }\end{array}$} & \multicolumn{2}{|c|}{$\begin{array}{c}\text { Economic Emission } \\
\text { Dispatch }\end{array}$} \\
\hline & & NSGA II & SPEA 2 \\
\hline $\mathrm{P}_{t 1} 175.1141$ & 131.2701 & 47.8544 & 125.2241 \\
\hline$P_{t 2} 242.6539$ & 220.0054 & 157.7517 & 270.0507 \\
\hline$P_{t 3} 304.6120$ & 225.0104 & 285.2191 & 243.0064 \\
\hline$P_{t 4} 147.6799$ & 147.5379 & 147.5379 & 176.5720 \\
\hline$P_{t 5} 166.2134$ & 150.3602 & 124.0388 & 163.4945 \\
\hline$P_{t 6} 136.7123$ & 149.5807 & 180.0000 & 133.8819 \\
\hline$P_{t 7} 173.7326$ & 76.4833 & 60.0000 & 117.9709 \\
\hline $\mathrm{P}_{t 8} 154.9804$ & 77.1193 & 179.4743 & 60.0577 \\
\hline$P_{t 9} 121.5496$ & 74.9862 & 91.3939 & 125.0197 \\
\hline$P_{t 10} 40.3942$ & 95.6814 & 108.0711 & 80.5614 \\
\hline$P_{t 11} 40.4158$ & 95.9912 & 40.2763 & 119.9426 \\
\hline$P_{t 12} 56.2225$ & 76.1652 & 61.9070 & 55.0000 \\
\hline$P_{t 13} 55.0172$ & 55.0118 & 107.3403 & 55.8733 \\
\hline $\mathrm{P}_{t 14} 421.4253$ & 135.3546 & 243.2763 & 257.7605 \\
\hline $\mathrm{P}_{t 15} 234.3023$ & 90.2354 & 284.8780 & 266.3629 \\
\hline$P_{t 16} 252.2307$ & 225.0035 & 236.0131 & 227.6083 \\
\hline$P_{t 17} 146.8343$ & 148.1660 & 180.0000 & 63.6185 \\
\hline $\mathrm{P}_{t 18} 147.2141$ & 149.1256 & 120.8225 & 152.0744 \\
\hline $\mathrm{P}_{t 19} 174.7218$ & 150.1015 & 126.8398 & 153.4561 \\
\hline $\mathrm{P}_{t 20} 161.7564$ & 73.8703 & 60.0000 & 79.5739 \\
\hline$P_{t 21} 148.2109$ & 76.5604 & 119.8093 & 135.8604 \\
\hline$P_{t 22} 180.0000$ & 73.7084 & 154.0689 & 76.2866 \\
\hline $\mathrm{P}_{t 23} 55.4384$ & 95.7966 & 78.8220 & 120.0000 \\
\hline $\mathrm{P}_{t 24} 41.4238$ & 97.1463 & 120.0000 & 120.0000 \\
\hline$P_{t 25} 57.7860$ & 76.1090 & 88.2034 & 98.9655 \\
\hline$P_{t 26} 55.5977$ & 76.2695 & 112.2056 & 74.3555 \\
\hline $\mathrm{P}_{c 1} 117.6495$ & 246.9607 & 195.6818 & 215.7340 \\
\hline $\mathrm{P}_{c 2} 70.9362$ & 125.7974 & 60.4244 & 74.7606 \\
\hline $\mathrm{P}_{c 3} 148.8926$ & 246.9461 & 222.8787 & 130.2030 \\
\hline $\mathrm{P}_{c 4} 103.4972$ & 125.8000 & 97.6660 & 118.7039 \\
\hline
\end{tabular}

Retrieval Number: C5655029320/2020@BEIESP DOI: 10.35940/ijeat.C5655.029320 Journal Website: www.ijeat.org
Published By:

Blue Eyes Intelligence Engineering

2309 \& Sciences Publication 
Multi-Region Combined Heat and Power Economic Emission Dispatch

\begin{tabular}{|c|c|c|c|}
\hline \multirow[t]{2}{*}{$\begin{array}{l}\text { Economic } \\
\text { Dispatch }\end{array}$} & \multirow{2}{*}{$\begin{array}{l}\text { Emission } \\
\text { Dispatch } \\
\text { NSGA II } \\
\end{array}$} & \multicolumn{2}{|c|}{$\begin{array}{c}\text { Economic Emission } \\
\text { Dispatch }\end{array}$} \\
\hline & & NSGA II & SPEA 2 \\
\hline $\begin{array}{ll}P_{c 5} & 10.4163\end{array}$ & 59.9163 & 47.7762 & 38.3283 \\
\hline $\mathrm{P}_{c 6} \quad 47.9396$ & 89.8480 & 82.6971 & 80.1689 \\
\hline $\mathrm{P}_{c 7} 149.0130$ & 246.8992 & 156.5276 & 213.4789 \\
\hline $\mathrm{P}_{c 8} \quad 74.6154$ & 125.6641 & 121.5002 & 105.6402 \\
\hline $\mathrm{P}_{c 9} 147.3443$ & 246.9531 & 135.0682 & 227.6502 \\
\hline$P_{c 10} 105.2674$ & 125.7584 & 82.4985 & 110.1486 \\
\hline$P_{c 11} 10.1667$ & 59.9512 & 36.7629 & 26.9498 \\
\hline $\mathrm{P}_{c 12} 80.2413$ & 89.9919 & 84.2810 & 77.5090 \\
\hline $\mathrm{H}_{c 1} 125.2917$ & 0.0016 & 60.0660 & 21.1935 \\
\hline $\mathrm{H}_{c 2} 101.7223$ & 32.1396 & 63.6122 & 10.9137 \\
\hline $\mathrm{H}_{c 3} 142.6570$ & 0 & 89.1739 & 1.6623 \\
\hline $\mathrm{H}_{c 4} 129.7772$ & 32.3555 & 5.1826 & 17.9133 \\
\hline $\mathrm{H}_{c 5} 40.1778$ & 0.0590 & 9.2503 & 33.9861 \\
\hline $\mathrm{H}_{c 6} 25.8558$ & 24.5429 & 21.3635 & 1.5788 \\
\hline $\mathrm{H}_{c 7} 142.9650$ & 0.1691 & 65.0978 & 18.7457 \\
\hline $\mathrm{H}_{c 8} 104.7792$ & 33.1855 & 0.3305 & 93.3041 \\
\hline $\mathrm{H}_{c 9} 142.0037$ & 0.1392 & 94.7179 & 29.1193 \\
\hline $\mathrm{H}_{c 10} 131.3721$ & 32.2791 & 104.3493 & 113.3349 \\
\hline $\mathrm{H}_{c 11} 40.0617$ & 0.1407 & 4.5180 & 10.1226 \\
\hline $\mathrm{H}_{c 12} 0.5230$ & 24.4440 & 7.8781 & 0 \\
\hline $\mathrm{H}_{h 1} 59.9604$ & 0.6000 & 57.4000 & 60.0000 \\
\hline $\mathrm{H}_{h 2} 59.9817$ & 8.8000 & 51.3000 & 31.3000 \\
\hline $\mathrm{H}_{h 3} 119.9880$ & 8.6000 & 113.4000 & 83.6000 \\
\hline $\mathrm{H}_{h 4} 119.9375$ & 0 & 106.5000 & 62.1000 \\
\hline $\mathrm{H}_{h 5} 717.0273$ & 2607.9 & 1250.8 & 1146.0 \\
\hline $\mathrm{H}_{h 6} 59.9968$ & 4.3000 & 33.9000 & 60.0000 \\
\hline $\mathrm{H}_{h 7} 59.9686$ & 0.8000 & 27.5000 & 59.5000 \\
\hline $\mathrm{H}_{h 8} 119.9926$ & 12.6000 & 120.0000 & 56.9000 \\
\hline $\mathrm{H}_{h 9} 119.9976$ & 3.2000 & 113.1000 & 97.3000 \\
\hline $\mathrm{H}_{h 10} 722.6231$ & 557.000 & 1372.0 & 1341.6 \\
\hline
\end{tabular}

\section{REFERENCES}

1. C. Wang and S. M. Shahidehpour, "A decomposition approach to nonlinear multi area generation scheduling with tie-line constraints using expert systems", IEEE Trans Power Syst., vol. 7, no. 4, pp. 1409-1418, 1992.

2. D. Streiffert, "Multi-area economic dispatch with tie line constraints", IEEE Trans. Power Syst. Vol. 10, no. 4, pp. 1946-1951, 1995.

3. Behnam Mohammadi-Ivatloo, Mohammad Moradi-Dalvand, Abbas Rabiee, "Combined heat and power economic dispatch problem solution using particle swarm optimization with time varying acceleration coefficients", Electric Power System Research 2013, 95 918.

4. M. Basu, "Group search optimization for combined heat and power economic dispatch", International Journal of Electrical Power \& Energy Systems, Volume 78, June 2016, Pages 138-147.

5. M. R. Gent and J. W. Lamont, "Minimum Emission Dispatch", IEEE Trans. on PAS, (90), pp. 2650-2660, 1971.

6. K. Deb and R. B. Agrawal, "Simulated binary crossover for continuous search space", Complex Systems, vol. 9, no. 2, pp. 115-148, 1995.

7. N. Srinivas and K. Deb, "Multiobjective function optimization using nondominated sorting genetic algorithms", IEEE Trans. on Evol Comput., vol. 2, no. 3, pp. 221-248, 1994.

8. K. Deb, A. Pratap, S Agarwal, and T. Meyarivan, "A fast and elitis multiobjective genetic algorithm: NSGA-II", IEEE Trans. on Evol Comput., vol. 6, no. 2, pp. 182-197, April 2002.

9. E. Zitzler, M. Laumanns, and L. Thiele, "SPEA2: Improving the Strength Pareto Evolutionary Algorithm", Swiss Federal Institute of Technology (ETH), Zurich, Switzerland. Technical report TIK- Report 103, May 2001.

10. Manisha Sharma, Manjaree Pandit, Laxmi Srivastava, "Reserve constrained multi-area economic dispatch employing differential evolution with time-varying mutation", International Journal of Electrical Power and Energy Systems, Volume 33, Issue 3, March, 2011, pp. 753-766.

11. M. Ghasemi, J. Aghaei, E. Akbari, S. Ghavidel and Li Li, "A differential evolution particle swarm optimizer for various types of multi-area economic dispatch problems", Energy, vol. 107, pp. 182195, 2016

12. F. J. Rooijers, R.A.M. van Amerongen, "Static economic dispatch for co-generation systems", IEEE Transactions on Power Systems 9 (3) (1994) 1392-1398.

13. Tao Guo, Henwood M. I., Ooijen M. van, "An algorithm for heat and power dispatch", IEEE Transactions on Power Systems 11 (4) (1996) 1778-1784.

14. C. T. Su, C. L. Chiang, "An incorporated algorithm for combined heat and power economic dispatch", Electric Power System Research 2004, 69 (2-3) 187-195.

15. K. Deb and R. B. Agrawal, "Simulated binary crossover for continuous search space", Complex Systems, vol. 9, no. 2, pp. 115-148, 1995.

16. M. R. Gent and J. W. Lamont, "Minimum Emission Dispatch", IEEE Transactions on power apparatus and systems, (90), pp. 2650-2660, 1971

\section{CONCLUSION}

In the current work, NSGA-II is recommended to solve complex multi-region combined heat and power economic emission dispatch problem. Simulation results attained from the recommended technique are compared with those attained from SPEA 2. It is seen that the recommended technique proffers a cutthroat performance.
Published By:

Blue Eyes Intelligence Engineering 2310 \& Sciences Publication 


\section{APPENDIX}

Table A.1: Data of section 1

\begin{tabular}{|c|c|c|c|c|c|c|c|c|}
\hline \multicolumn{9}{|c|}{ Thermal generators } \\
\hline Unit & $\mathrm{P}^{\mathrm{mil}}$ & ${ }^{n} \mathrm{P}^{\mathrm{n}}$ & ${ }^{\mathrm{ax}} a$ & $b$ & $C$ & $\mu$ & $\kappa$ & $\pi$ \\
\hline 1 & 0 & 680 & 160 & 3.6 & 0.0021 & 5.4289 & 0.0351 & 0.000 \\
\hline 2 & 0 & 360 & 130 & 3.8 & 0.0017 & 4.2895 & 0.0411 & 0.00040 \\
\hline 3 & 0 & 360 & 130 & 3.8 & 0.0017 & 4.2895 & 0.0411 & 0.00040 \\
\hline 4 & 60 & 180 & 100 & 4.0 & 0.0023 & 4.2669 & 0.0545 & 0.000 \\
\hline 5 & 60 & 180 & 100 & 4.0 & 0.0023 & 4.2669 & 0.0545 & 0.000 \\
\hline 6 & 60 & 180 & 100 & 4.0 & 0.0023 & 4.2669 & 0.0545 & 0.000 \\
\hline 7 & 60 & 180 & 120 & 3.5 & 0.0035 & 4.2669 & 0.0254 & 0.00036 \\
\hline 8 & 60 & 180 & 120 & 3.5 & 0.0035 & 4.2669 & 0.0254 & 0.000 \\
\hline 9 & 60 & 180 & 120 & 3.5 & 0.0035 & 4.2669 & 0.0254 & 0.00036 \\
\hline 10 & 40 & 120 & 150 & 4.6 & 0.0105 & 1.3859 & 0.0327 & 0.00032 \\
\hline 11 & 40 & 120 & 150 & 4.6 & 0.0105 & 1.3859 & 0.0327 & 0.000 \\
\hline 12 & 55 & 120 & 140 & 3.8 & 0.0015 & 1.4385 & 0.0232 & 0.000 \\
\hline 13 & 55 & 120 & 140 & 3.8 & 0.0015 & 1.4385 & 0.0232 & 0.000 \\
\hline
\end{tabular}

Unit $\begin{array}{llllllll}\alpha & \beta & \gamma & \delta & \varepsilon & \xi & \tau\end{array}$

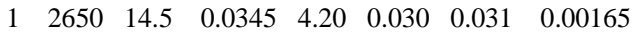

$2 \begin{array}{llllllll}2 & 1250 & 36.0 & 0.0435 & 0.60 & 0.027 & 0.011 & 0.00220\end{array}$

$\begin{array}{llllllll}3 & 2650 & 14.5 & 0.0345 & 4.20 & 0.030 & 0.031 & 0.00165\end{array}$

$\begin{array}{llllllll}4 & 1250 & 36.0 & 0.0435 & 0.60 & 0.027 & 0.011 & 0.00220\end{array}$

$\begin{array}{llllllll}5 & 2650 & 34.5 & 0.1035 & 2.20 & 0.025 & 0.051 & 0.00140\end{array}$

$\begin{array}{llllllll}6 & 1565 & 20.0 & 0.0720 & 2.34 & 0.020 & 0.040 & 0.00110\end{array}$

Heat-only units

Unit $\mathrm{H}^{\min } \mathrm{H}^{\max } \varphi \quad \eta \quad \lambda \quad \rho$

$\begin{array}{rrrrrrr}1 & 0 & 60 & 950 & 2.0109 & 0.038 & 0.0018 \\ 2 & 0 & 60 & 950 & 2.0109 & 0.038 & 0.0018 \\ 3 & 0 & 120 & 480 & 3.0651 & 0.052 & 0.0017 \\ 4 & 0 & 120 & 480 & 3.0651 & 0.052 & 0.0017 \\ 5 & 0 & 2695.2 & 950 & 2.0109 & 0.038 & 0.0016\end{array}$

Table A.2: Restricted effective area of 1 thermal generators of section 1

\begin{tabular}{|c|c|c|c|}
\hline Unit & Precinct 1, MW & Precinct 2, MW & $\begin{array}{c}\text { Precinct 3, } \\
\text { MW }\end{array}$ \\
\hline 1 & {$[180,195]$} & {$[260,335]$} & {$[390,420]$} \\
\hline 2 & {$[30,40]$} & {$[180,220]$} & {$[305,335]$} \\
\hline 3 & {$[30,45]$} & {$[190,225]$} & {$[305,335]$} \\
\hline 10 & {$[45,55]$} & {$[65,75]$} & - \\
\hline 11 & {$[45,55]$} & {$[65,75]$} & - \\
\hline
\end{tabular}

\section{AUTHORS PROFILE}

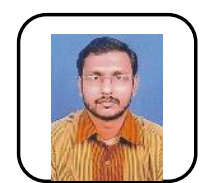

Suman Kumar Dey, received his B.Tech in Electrical Engineering from Makaut (Formerly WBUT) in 2008 and M.Tech in Electrical Power from Calcutta University in 2013. Currently, he is pursuing his Ph.D. in Electrical Engineering under the Department of Power Engineering, Jadavpur University, Kolkata. His area of interest is Power System, Electric Drives and renewable energy.

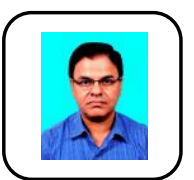

Deba Prasad Dash, received his B.Tech and M.Tech degrees under Utkal University in 1997 and 2001, respectively. He has done his Ph.D. from Jadavpur University, Kolkata in 2011. Currently, he is working as Associate Professor, Department of Electrical Engineering, Government College of Engineering, Kalahandi. His area of interest includes power system optimization and renewable energy sources.

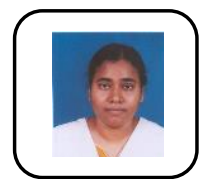

Mousumi Basu, received the bachelor degree, master degree and Ph.D. degree from Jadavpur Universty, Kolkata, India, in 1991, 1993 and 2003 respectively. She is a professor at Power Engineering Department of Jadavpur Universty. Her research is focused on power system optimization, soft computing techniques and renewable energy sources.
Published By: 